\section{Estudo \\ CoDebate}

em Testão

Planeiamento

\title{
ANÁLISE DO DESEMPENHO DO PROCESSAMENTO DE ERVA- MATE NO ARRANJO PRODUTIVO LOCAL ALTO TAQUARI - RS
}

\author{
Leticia Andrea Chechi ${ }^{1}$, Caroline Soares da Silveira ${ }^{2}$, Glauco Schultz ${ }^{3}$
}

\begin{abstract}
Resumo: O Polo Ervateiro do Alto Taquari - RS é um importante produtor e beneficiador de erva-mate no Estado e a nível nacional. A problemática deste trabalho se refere a importância do fornecimento local de matériaprima, equipamentos, relaçôes estabelecidas e mão de obra no desempenho produtivo deste APL ervateiro. Nesse contexto, o objetivo do estudo é discutir a dinâmica de processamento da erva-mate no APL ervateiro do Alto Taquari, através de características produtivas locais, e a relação destas com os resultados apresentados pela matriz importância-desempenho. A pesquisa foi realizada no polo ervateiro do Alto Taquari - RS, mais especificamente nos municípios de Ilópolis, Arvorezinha, Anta Gorda e Putinga, no segundo semestre de 2015 e no segundo semestre de 2016, sendo entrevistados 35 gestores de ervateiras e 6 agentes locais. Os resultados mostraram que os fatores de produção como custo e qualidade da matéria-prima, custo e capacitaçáo da mão de obra, disponibilidade de assistência técnica são considerados adequados no APL, em relação à sua importância e desempenho. Os fatores que necessitam de açóes para o seu melhoramento, como disponibilidade de matériaprima e de mão de obra, revelam a característica de relaçóes específicas em uma mistura de cooperaçáo e competiçáo, enquanto o custo de aquisição e porte e capacidade de maquinários, sugere, de acordo com a pesquisa realizada, ser uma dificuldade desta tipologia de arranjo. Conclui-se que, com a maioria dos fatores analisados alocados na zona adequada da matriz importância - desempenho, o processamento da erva-mate no Alto Taquari é considerado satisfatório.
\end{abstract}

Palavras-chave: Erva-mate. Fatores de produção; APL Alto Taquari - RS; matriz importância-desempenho.

1 Engenheira Florestal, Mestre e doutoranda em Desenvolvimento Rural, Universidade Federal do Rio Grande do Sul (UFRGS), leticia.chechi@ufrgs.br

2 Engenheira Florestal, Mestre e Doutoranda em Agronegócios, Universidade Federal do Rio Grande do Sul (UFRGS), carolinesoaresef14@hotmail.com

3 Engenheiro Agrícola, Mestre e Doutor em Agronegócios, Professor Adjunto na Universidade Federal do Rio Grande do Sul (UFRGS), glauco.schultz@ufrgs.br 


\title{
ANALYSIS OF PERFORMANCE OF THE PROCESSING OF ERVA- MATE IN THE LOCAL PRODUCTION ARRANGEMENT ALTO TAQUARI - RS
}

\begin{abstract}
The yerba-mate producer pole of Alto Taquari - RS is an important producer and beneficiator of yerba mate at state and national levels. The problematic of this study refers to the importance of the local supply of raw material, equipment, established relations and manpower in the productive performance of this yerba mate arrangment. In this context, the objective of this study is to discuss the processing dynamics of yerbamate in the Taquari yerba-mate APL, through local productive characteristics and their relation with the results presented by the importance-performance matrix. The research was carried out in the municipalities of Ilópolis, Arvorezinha, Anta Gorda and Putinga, in the second semester of 2015 and in the second semester of 2016, interviewed 35 managers of managers of yerba-mate industries and 6 local agents. The results showed that the factors of production such as cost and raw material quality, cost and labor capacity, availability of technical assistance are considered adequate in APL, in relation to their importance and performance. Factors that require action for improvement, such as availability of raw materials and labor, reveal the characteristic of specific relationships in a mixture of cooperation and competition, while the cost of acquisition, size and machinery capacity, suggests, according to the research carried out, a difficulty of this type of arrangement. It is concluded that, with most of the analyzed factors allocated in the appropriate zone of the importance-performance matrix, the processing of yerba-mate in Alto Taquari is considered satisfactory.
\end{abstract}

Keywords: yerba-mate; factors of production; APL Alto Taquari - RS; importance-performance matrix.

\section{Introduçáo}

Os Arranjos Produtivos Locais (APLs) são definidos como aglomeração de organizaçóes vinculadas a uma atividade comum, ligadas por fluxos de bens e serviços, nos diversos elos da cadeia produtiva (SANTOS; GUARNERI, 2000). De acordo com os estudos realizados, desde Marshall (1982), sobre os distritos industriais, a proximidade espacial das organizaçôes confere vantagens às organizaçóes, as tornando mais competitivas no mercado.

A oferta local de matéria-prima e insumos, relaçóes de confiança, a transmissão de informaçóes, o conhecimento tácito, formas de governança, mão de obra qualificada, proximidade de mercados consumidores, redução dos custos de transação, são algumas das características de APLs (CASSIOLATO; SZAPIRO, 2003; VARGAS, 2002; SUZIGAN; GARCIA; FURTADO, 2002). No entanto, a competitividade depende de melhorias constantes em vários aspectos, como nos processos gerenciais, capacitação dos recursos humanos, tecnologia, equipamentos, distribuição, processos produtivos, dentre outros.

Para isso, a matriz importância-desempenho se apresenta como uma ferramenta útil para aferir o grau de importância de determinado fator, bem como o desempenho que este está apresentando. De acordo com Slack, Chambers e Johnston (2002), medir o desempenho das operaçôes produtivas é necessário para se planejar açóes de melhoramento, na qual a urgência na direção de prioridades é determinada em razão do seu atual desempenho.

O Polo Ervateiro do Alto Taquari - RS, que compreende onze municípios, se destaca na produçáo e beneficiamento de erva-mate no estado. No ano de 2015, o esse Polo foi responsável por 58\% da produção de erva-mate no Rio Grande do Sul (IBGE, 2015), e ao final da pesquisa de campo, em 2016, contava com 62 indústrias ervateiras. Considerado 
essa região como um arranjo produtivo de erva-mate, a questão apresentada é: qual a importância do fornecimento local de matéria-prima, equipamentos, relaçóes estabelecidas e mão de obra no desempenho produtivo do APL?

Nesse contexto, o objetivo do trabalho é discutir a dinâmica de processamento da erva-mate no APL ervateiro do Alto Taquari, através de características produtivas locais, e a relação destas com os resultados apresentados pela matriz importância-desempenho. $\mathrm{O}$ trabalho está estruturado em quatro partes além desta introdução. A primeira aborda um breve diálogo sobre APLs, seguido pelas características relacionadas à matriz importânciadesempenho. A seção seguinte aborda a metodologia seguida para a realização do estudo. A terceira parte apresenta os principais resultados e a discussão dos mesmos em relação às abordagens apresentadas. Por fim, são apresentadas consideraçóes acerca das características locais de processamento, e a relação com a importância e desempenho dessas em um APL.

\subsection{Arranjos Produtivos Locais (APLs) e suas principais características}

A discussão referente à proximidade espacial de organizaçôes e benefícios relacionados iniciou com os estudos de Marshall (1982), sobre os distritos industriais ingleses, no final do século XIX. Os argumentos deste autor para o estudo dos aglomerados reforçaram-se empiricamente no fato de que algumas empresas, apesar de serem pequenas, desempenhavam bem suas atividades, superando o desempenho de grandes indústrias presentes na Inglaterra.

A vantagem decorreria da concentração convergente de atividades produtivas; do movimento contínuo de trocas e informaçôes; da localização concentrada de fornecedores e de clientes; da notoriedade alcançada pelo local ou região; pela transmissão e propagação do conhecimento científico e tecnológico (MARSHALL, 1982).

Seguindo a abordagem marshalliana, Schmitz (1989) caracteriza aglomeraçóes como a concentração geográfica de um setor ou cadeia de produção. Nestas, a desverticalização do processo produtivo favoreceria a formação de redes de cooperaçáo, gerando uma complementariedade entre as organizaçôes, que contemplam também instituiçóes de pesquisa, de capacitação e de coordenação local. As aglomeraçóes possibilitam ganhos competitivos por compreender pequenas e médias empresas, articulaçóes a montante e a jusante, baseadas em trocas comerciais e não comerciais, elementos sociais e culturais em comum e o suporte de uma rede de instituições, públicas e privadas (RABELLOTTI, 1995).

De acordo com Brusco (1992), as empresas presentes em uma aglomeração ligam-se umas às outras através de relações específicas, em uma mistura de competição e cooperação. Schmitz (1995) também trabalha a dinâmica de cooperação e conflito em aglomeraçóes produtivas, ao desenvolver o conceito de eficiência coletiva proveniente das externalidades locais e da ação conjunta de empresas. Contudo, de acordo com este autor, a eficiência coletiva não exclui o conflito ou a competição, mas torna o mercado mais transparente e provoca a rivalidade local. Porter (1999), utilizando o conceito de cluster, caracteriza as concentraçóes geográficas sem necessariamente visualizar o desenvolvimento de cooperação entre os agentes, atendo-se mais a capacidade competitiva das mesmas.

A discussão desenvolvida por autores da escola californiana, como Storper (1997), Scott (1998) e Markusen et al. (1999), referem-se à flexibilidade da produção vinculada 
à questão das aglomeraçóes via uma análise dos custos de transação associados às reaçóes interfirmas. De acordo com os autores, as aglomeraçóes são vistas como minimizadoras de custos de transação.

Os pesquisadores franceses, tendo como principal representante Courlet (1993), desenvolveram a noção de sistemas industriais localizados ou sistemas produtivos locais, embasados nas relaçóes de colaboração de médio e longo prazo, entre empresas que trabalham conjuntamente conforme acordos específicos. Esses sistemas não seriam necessariamente formados por pequenas e médias empresas, devido ao fato de existirem relaçóes territorializadas entre grandes empresas e grupos de pequenas e médias empresas (COURLET, 1993). A proximidade geográfica das empresas desenvolveria um tecido espacial de conhecimentos, o que favorece os processos inovativos de conotação territorializada (COURLET, 2001).

O conhecimento também está presente nas pesquisas de tradição neoschumpeteriana e evolucionista, ressaltando a importância do mesmo no desenvolvimento de inovaçóes e a busca pela diferenciação e obtenção do lucro. De acordo com os autores dessa corrente, a inovação é um processo sistêmico, onde as firmas não inovam isoladamente, mas interagindo com outras organizaçóes, tendo influência do contexto institucional local (EDQUIST, 1997; LASTRES, LEMOS E VARGAS, 2000).

A partir dos estudos de Marshall (1982) dos distritos industriais, muitos outros foram desenvolvidos, trabalhando diferentes nomenclaturas, como clusters (PORTER, 1998), sistemas produtivos locais (COURLET, 1993), arranjos produtivos locais (CASSIOLATO; LASTRES, 2003), arranjos e sistemas produtivos e inovativos locais (CASSIOLATO; SZAPIRO, 2003), dentre outros. Mesmo com abordagens que buscam dar diferentes enfoques para os efeitos e benefícios da proximidade local de agentes, apresentam convergência principalmente da dimensão localizada da competitividade e da inovação (LEMOS, 1997).

As distinções conceituais, de acordo com Suzigan et al. (2002), resumem-se a graus variados de desenvolvimento, de integração da cadeia produtiva, da articulação e interação entre agentes e instituiçóes locais, e de capacidades sistêmicas para a inovação. Dentre as diferentes nomenclaturas, a denominação de Arranjos Produtivos Locais (APLs) é amplamente utilizada, inclusive para construção de políticas públicas.

Para o Banco Nacional de Desenvolvimento (BNDES), conforme descrito por Santos e Guarneri (2000), APLs são definidos como um fenômeno das economias de aglomeração, associadas à proximidade física das empresas ligadas por fluxos de bens e serviços. A concentração geográfica permite ganhos mútuos e operações mais produtivas, destacando-se o papel das instituições locais para a organização das empresas, visando os ganhos coletivos.

Características como oferta de matéria-prima e outros insumos, relações de confiança, redução dos custos de transação, conhecimento tácito, formas de governança inerente às relaçôes entre diferentes segmentos de atores, mão de obra qualificada, proximidade de mercados consumidores, dentre outras, caracterizam um APL e configuram vantagens às 
organizações que fazem parte desse arranjo (CASSIOLATO; SZAPIRO, 2003; VARGAS, 2002; SUZIGAN; GARCIA; FURTADO, 2002).

De acordo com Porter (1999), as vantagens competitivas das empresas estão associadas ao tamanho, idade, setor, níveis de habilidades e ao ambiente no qual são localizadas, influenciadas por quatro aspectos, quais sejam: a) condiçóes dos fatores internos e externos do aglomerado, como a disponibilidade de infraestrutura, capital, empreendedorismo e inovação; b) condiçóes de exigência, no desenvolvimento do produto, sistemas locais de compras e distribuição, tamanho do mercado e aglomeração; c) industrias relacionadas e de suporte, como fornecedores e clientes que são também firmas avançadas; e, d) estratégia de negócio, estrutura e competição, afetando como as firmas são organizadas, gerenciadas, competem ou cooperam umas com as outras, incluindo estruturas institucionais e o papel do governo.

Nesse sentido, a simples concentração de empresas não traz vantagens competitivas. De acordo com Cassiolato; Lastres (2003), Puga (2003), Suzigan (2001), a competitividade depende de melhorias constantes em processos gerenciais, capacitação dos recursos humanos, tecnologia, equipamentos, distribuição, processos produtivos, dentre outros.

As melhorias que podem ser estabelecidas visualizando aumento de vantagens competitivas necessitam de um estudo prévio para determinar quais os fatores, em ordem de importância, necessitam de açóes de melhoramento dentro das organizaçóes, para que seja possível estabelecer estratégias para corrigi-las. O tópico a seguir visa discorrer sobre a teoria associada à ferramenta da matriz importância - desempenho, na qual demonstra como a importância e o desempenho de fatores condicionantes da competitividade são tratados segundo os autores Slack, Chambers e Johnston (2002).

\subsection{Teoria Associada à Matriz Importância - Desempenho}

Na proposta de Slack, Chambers e Johnston (2002), o desempenho é definido como o grau em que a produção preenche os cinco objetivos de desempenho em qualquer momento, satisfazendo os seus consumidores. Os objetivos de desempenho variam, estes são vistos como as dimensóes do desempenho global que satisfazem os consumidores. Os objetivos de desempenho propostos na metodologia de Slack, Chambers e Johnston (2002) são: qualidade, velocidade, confiabilidade, flexibilidade e custo.

A matriz importância - desempenho é uma ferramenta utilizada na administração da produção de bens e serviços para aferir o grau de importância e desempenho para os fatores competitivos dos produtos e/ou processos produtivos. Embora seja uma ferramenta de análise amplamente utilizada na área de produção, a matriz importância - desempenho apresenta características que possibilitam sua aplicação a outras áreas da administração, como por exemplo, a gestão de pessoas (VALERIANO, TALAMINI e OLIVEIRA, 2011).

Segundo Kowalski e Fernandes (2008), uma matriz de importância - desempenho é um método de controle utilizado na avaliação de produtos ou procedimentos. É construída por meio de informaçóes obtidas de diversas outras empresas do mesmo setor, desta forma, constitui-se um padrão, uma base de mensuração, baseando a análise das atividades individualmente. 
Um estudo realizado por Betto, Ferreira e Talamini (2010), em relação a importância e o desempenho de cada uma das variáveis, mostrou que o método da matriz importância - desempenho fornece à empresa estudada subsídios necessários e informaçóes valiosas a respeito das experiências e expectativas de seus clientes e da própria empresa. Isto contribui para a tomada de decisão tornando-a mais competitiva no mercado. Ainda, afirma-se que a pesquisa, neste caso, esclarece a percepção e a satisfação das populaçóes estudadas quanto aos produtos e serviços oferecidos pela empresa.

As necessidades e preferências de consumidores e o desempenho e atividades dos concorrentes são consideradas duas importantes influências na maneira com que a produção decide qual objetivo de desempenho requer atenção. A necessidade dos consumidores tem o objetivo de criar bens e serviços de tal forma a atingir as necessidades dos consumidores que, por sua vez, definem a importância dentro da operação (SLACK, CHAMBERS e JOHNSTON, 2002).

Os concorrentes são pontos de comparação em relação ao qual a operação pode julgar seu desempenho. O desempenho que mais interessa é o que leva a operação a superar os níveis de desempenho atingidos por seus concorrentes. Tanto a importância como o desempenho precisam ser considerados em conjunto antes que qualquer julgamento possa ser feito quanto às prioridades relativas para melhoramentos e para a priorização dos seus objetivos (SLACK, CHAMBERS e JOHNSTON, 2002).

Segundo Slack, Chambers e Johnston (2002), todas as operações produtivas precisam de alguma forma de medida de desempenho, como pré-requisito para melhoramento, na qual a urgência na direção de prioridades é determinada em razão do seu atual desempenho. Este desempenho é julgado em relação aos seus concorrentes.

Em uma matriz importância - desempenho mostra-se as prioridades de melhoramento dadas a cada fator competitivo na qual pode ser avaliada, com base em sua importância e em seu desempenho. A matriz posiciona cada fator competitivo de acordo com seus escores ou classificações. A Matriz Importância x Desempenho é dividida em zonas de prioridades de melhoramento, conforme descritos, a seguir, segundo Slack, Chambers e Johnston (2002).

Os fatores competitivos indicados na Zona "Adequada” e, portanto, acima da fronteira de aceitabilidade, devem ser considerados como satisfatórios. Os fatores competitivos indicados na Zona de "Melhoramento", por estarem abaixo da fronteira de aceitabilidade, são passíveis de ações de melhoramento. Os fatores de competitividade na Zona de "Ação Urgente" indicam que são importantes para os consumidores, mas apresentam um desempenho relativamente baixo. Portanto, esses devem ser prioritários em receber açóes de melhoria.

Os fatores competitivos indicados na Zona de "Excesso" são relativamente pouco importantes para os consumidores. Contudo, a empresa apresenta um alto grau de desempenho nestes fatores. Isso indica uma alocação de recursos/esforços em fatores pouco valorizados pelos clientes. Neste caso, a disponibilidade de recursos da empresa deverá indicar a manutenção dos níveis de desempenho ou a realocação de recursos em fatores que carecem de melhor desempenho. 


\section{Metodologia}

Considerando a classificação de Gil (2007), o método da pesquisa, quanto aos objetivos, se caracteriza como descritivo, objetivando discutir a dinâmica de produção da erva-mate no Polo Ervateiro do Alto Taquari - RS, considerado neste trabalho como um APL ervateiro, através de dados produtivos locais e da relação importância/desempenho. De acordo com Triviños (1987), a pesquisa descritiva exige uma série de informaçôes do pesquisador, possibilitando descrever os fatos e fenômenos de determinada realidade. Ainda, podem se estabelecer relaçóes entre variáveis, buscando identificar e comparar determinados aspectos.

A pesquisa foi realizada no Polo Ervateiro do Alto Taquari - RS, mais especificamente nos municípios de Ilópolis, Arvorezinha, Anta Gorda e Putinga, os principais municípios produtores de erva-mate do arranjo. De acordo com dados do IBGE, em 2015, o polo ervateiro Alto Taquari foi responsável por mais de $60 \%$ da produção de erva-mate do estado do Rio Grande do Sul. A localização do polo ervateiro pode ser visualizada na Figura 1.

Figura 1- Região de Realização do Estudo

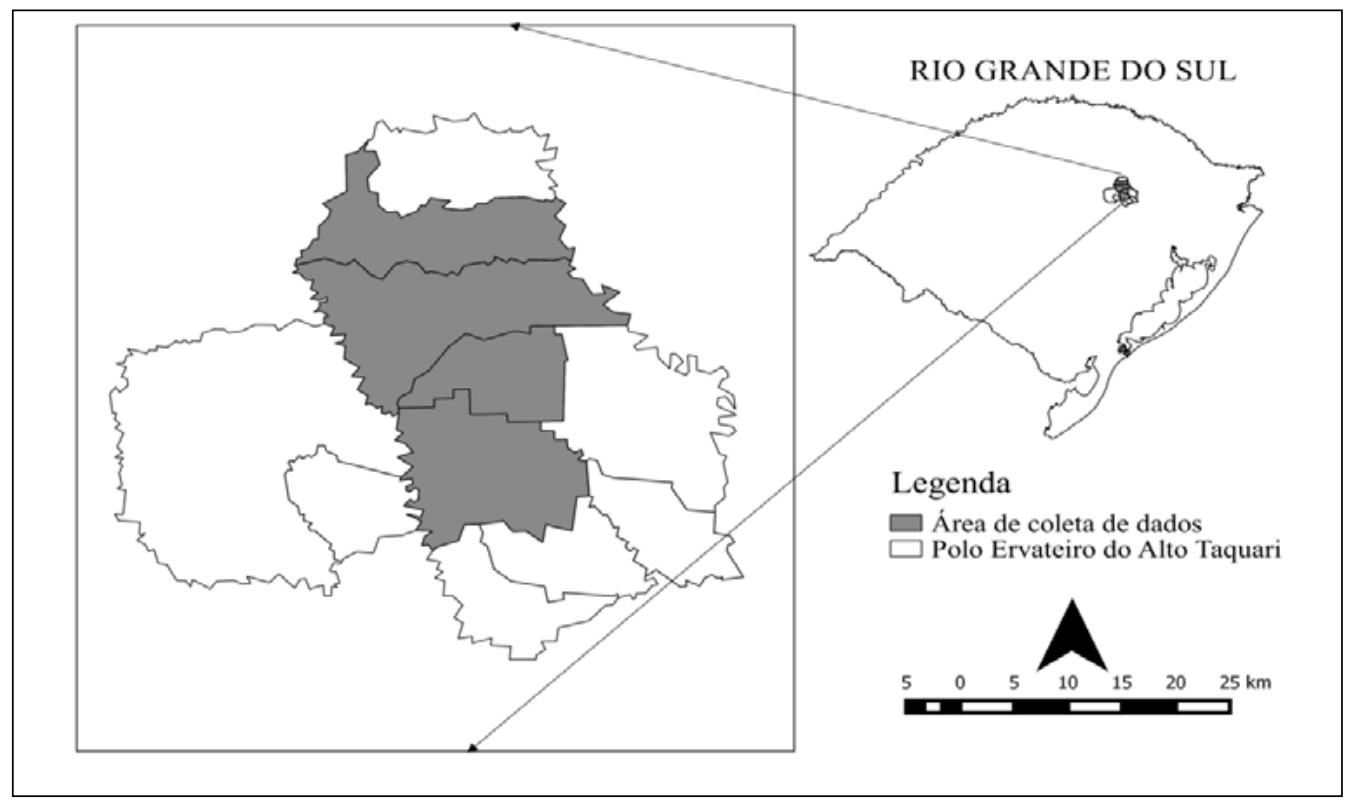

Fonte: Elaborado pelos autores (2017).

Foram coletados dados primários, em dois blocos, a saber: a) dados referentes à produção de erva-mate, representatividade em relação a outras atividades, origem da matéria prima, equipamentos e vantagens relacionadas, perfil da mão de obra; e, b) dados quantitativos referentes à importância e o desempenho dos seguintes fatores de produção: custo da matéria-prima, qualidade da matéria-prima, disponibilidade de matéria-prima, custo da mão de obra, capacitaçáo da mão de obra, disponibilidade de mão de obra, 
disponibilidade de assistência técnica, custo de aquisição de maquinários, qualidade dos maquinários e porte e capacidade de maquinários.

A coleta dos dados ocorreu em dois momentos, no segundo semestre de 2015, e no segundo semestre de 2016, sendo as entrevistas realizadas em ambos os períodos. Ao todo foram entrevistados 35 gestores de ervateiras e 6 agentes locais, produtor, representante de sindicato, intermediário, representante de instituto, representante do poder público municipal, e técnico ${ }^{4}$, selecionados de maneira intencional pelos pesquisadores. De acordo com Richardson (2009), na definição não probabilística intencional selecionamse características presentes no plano das hipóteses formuladas, relacionando-se intencionalmente, apresentando como representativa do universo escolhido, e ainda, de acordo com a proximidade do pesquisador e recursos disponíveis, buscando responder o problema de pesquisa.

Os dados quantitativos referentes à importância e desempenho foram analisados através da análise da estatística descritiva e utilizando a ferramenta da matriz importância desempenho, proposta por Slack, Chambers e Johnston (2002). Para tanto, utilizou-se um questionário estruturado, na qual cada pergunta sobre os fatores de produção apresentou dois níveis de escala Likert, a primeira varia de 1-7 pontos, 1 para pouco importante até 7 para muito importante e a segunda varia também de 1-7 pontos, 1 para pouco grave até 7 para muito grave, conforme a necessidade da aplicação da matriz importância - desempenho.

Segundo Morais (2010), a estatística descritiva pode ser considerada como um conjunto de técnicas analíticas utilizado para resumir o conjunto de dados recolhidos numa dada investigação, na qual geralmente são organizados através de números, tabelas e gráficos. O principal objetivo desta análise é proporcionar relatórios que apresentem informaçóes sobre tendência central e a dispersão dos dados. Nas medidas de tendência central, tem-se a média aritmética, moda e mediana e nas medidas de dispersão, tem-se a variância e o desvio padrão. Ademais, analisou o valor máximo e o valor mínimo apontado pelos respondentes, para auxiliar na análise dos dados.

Os dados gerados pela pesquisa foram tabulados e organizados nos programas Microsoft Office Excel e o software SPSS ${ }^{\oplus}$ (2003) (Statistical Package for Social Sciences), utilizando-se dos seus recursos de cálculos, recodificação dos dados, análises e representaçóes gráficas.

\section{Resultados e Discussão}

Os resultados e discussóes do presente artigo estão divididos em dois subitens: o primeiro apresenta os resultados de abordagem quantitativa, obtidos da aplicação da ferramenta matriz-importância desempenho de Slack, Chambers e Johnston (2002), na qual tem como objetivo alocar os fatores de produção em ordem de importância e desempenho para os industrialistas ervateiro e busca relacionar estes dados com as características observadas no arranjo produtivo. O segundo aborda as características produtivas do APL

4 Os Agentes Locais são referenciados no trabalho como Agente Local 1, Agente Local 2, até o 6, na ordem apresentada. 
ervateiro Alto Taquari, na qual apresenta uma discussão qualitativa das características produtivas analisadas.

\subsection{Discussóes dos Resultados da Aplicaçáo da Matriz Importância - Desempenho}

Os fatores de produção, na qual se admite como uma proposta de dimensão condicionante do desempenho das indústrias ervateiras são todos aqueles recursos utilizados para obter um produto ou serviço em um determinado processo de produção. Estes fatores de produção, relacionados ao processamento de erva-mate, juntamente com os seus respectivos valores obtidos na aplicação da análise estatística, estão detalhados na Tabela 1. Nesta etapa dos resultados e discussóes, objetivou-se, através de dados quantitativos, ordenar os fatores de produção utilizados no setor ervateiro quanto as necessidades de açóes de melhoramento nas indústrias para que estas obtenham um melhor desempenho e consequentemente, se tornem mais competitivas no mercado.

Tabela 1 - Estatística Descritiva dos Fatores de Produção

\begin{tabular}{|c|c|c|c|c|}
\hline $\begin{array}{c}\text { FATORES DE } \\
\text { DESEMPENHO }\end{array}$ & SIGLA & \multicolumn{3}{|c|}{ ESTATÍSTICA DESCRITIVA } \\
\hline & & & Importância & Desempenho \\
\hline \multirow{4}{*}{ Custo da Matéria-Prima } & \multirow{4}{*}{1} & Média & 5,59 & 4,63 \\
\hline & & Variância & 1,94 & 3,17 \\
\hline & & Valor Máximo & 7 & 7 \\
\hline & & Valor Mínimo & 2 & 1 \\
\hline \multirow{4}{*}{$\begin{array}{l}\text { Qualidade da Matéria- } \\
\text { Prima }\end{array}$} & \multirow{4}{*}{2} & Média & 6,81 & 4,78 \\
\hline & & Variância & 0,31 & 3,49 \\
\hline & & Valor Máximo & 7 & 7 \\
\hline & & Valor Mínimo & 5 & 1 \\
\hline \multirow{4}{*}{$\begin{array}{l}\text { Disponibilidade de } \\
\text { Matéria-Prima }\end{array}$} & \multirow{4}{*}{3} & Média & 5,78 & 4,00 \\
\hline & & Variância & 1,79 & 3,38 \\
\hline & & Valor Máximo & 7 & 7 \\
\hline & & Valor Mínimo & 3 & 1 \\
\hline \multirow{4}{*}{ Custo da Mão de Obra } & \multirow{4}{*}{4} & Média & 5,37 & 4,48 \\
\hline & & Variância & 1,78 & 2,80 \\
\hline & & Valor Máximo & 7 & 7 \\
\hline & & Valor Mínimo & 3 & 1 \\
\hline \multirow{4}{*}{$\begin{array}{c}\text { Capacitação da Mão de } \\
\text { Obra }\end{array}$} & \multirow{4}{*}{5} & Média & 5,85 & 4,48 \\
\hline & & Variância & 1,67 & 3,87 \\
\hline & & Valor Máximo & 7 & 7 \\
\hline & & Valor Mínimo & 3 & 1 \\
\hline
\end{tabular}




\begin{tabular}{|c|c|c|c|c|}
\hline $\begin{array}{c}\text { FATORES DE } \\
\text { DESEMPENHO }\end{array}$ & SIGLA & \multicolumn{3}{|c|}{ ESTATÍSTICA DESCRITIVA } \\
\hline & & & Importância & Desempenho \\
\hline \multirow{4}{*}{$\begin{array}{c}\text { Disponibilidade de Mão } \\
\text { de Obra }\end{array}$} & \multirow{4}{*}{6} & Média & 5,48 & 3,74 \\
\hline & & Variância & 1,03 & 2,58 \\
\hline & & Valor Máximo & 7 & 6 \\
\hline & & Valor Mínimo & 4 & 1 \\
\hline \multirow{4}{*}{$\begin{array}{l}\text { Disponibilidade de } \\
\text { Assistência Técnica }\end{array}$} & \multirow{4}{*}{7} & Média & 5,70 & 4,48 \\
\hline & & Variância & 2,45 & 4,03 \\
\hline & & Valor Máximo & 7 & 7 \\
\hline & & Valor Mínimo & 1 & 1 \\
\hline \multirow{4}{*}{$\begin{array}{c}\text { Custo de Aquisição de } \\
\text { Maquinários }\end{array}$} & \multirow{4}{*}{8} & Média & 5,74 & 4,19 \\
\hline & & Variância & 2,28 & 3,31 \\
\hline & & Valor Máximo & 7 & 7 \\
\hline & & Valor Mínimo & 2 & 1 \\
\hline \multirow{4}{*}{$\begin{array}{l}\text { Qualidade dos } \\
\text { Maquinários }\end{array}$} & \multirow{4}{*}{9} & Média & 6,44 & 4,41 \\
\hline & & Variância & 0,64 & 4,33 \\
\hline & & Valor Máximo & 7 & 7 \\
\hline & & Valor Mínimo & 4 & 1 \\
\hline \multirow{4}{*}{$\begin{array}{c}\text { Porte e Capacidade de } \\
\text { Maquinários }\end{array}$} & \multirow{4}{*}{10} & Média & 5,85 & 3,96 \\
\hline & & Variância & 0,98 & 2,34 \\
\hline & & Valor Máximo & 7 & 7 \\
\hline & & Valor Mínimo & 4 & 1 \\
\hline
\end{tabular}

Fonte: Elaborado pelos Autores (2017).

Conforme a matriz importância - desempenho, apresentada abaixo, na Figura 2, os itens que estão alocados próximos à fronteira de aceitabilidade, como é o caso dos fatores (3) e (8), disponibilidade de matéria prima e custo de aquisição de maquinários. Essas se encontram em transição entre a zona de melhoramento e a zona adequada, pois as suas respectivas médias correspondem a 5,78 e 5,74, apontadas pelos agentes como de alta importância, porém com o desempenho 4,00 e 4,19 não se constituem como um problema para o setor, sendo assim não necessitam de ações de melhoramento.

A variância, como pode ser observada nestes dois fatores, é menor em relação ao grau de importância do que em relação ao grau de desempenho. O valor mínimo apontado foi de 2 pontos para importância e o valor máximo atingiu 7 pontos na escala. Em relação ao grau de desempenho, o valor mínimo atribuído pelos agentes foi de 1 ponto e o valor máximo foi de 7 pontos, configurando um intervalo maior e alta variação entre as opçóes dos respondentes. 
Figura 2 - Matriz Importância - Desempenho - Fatores de Produção

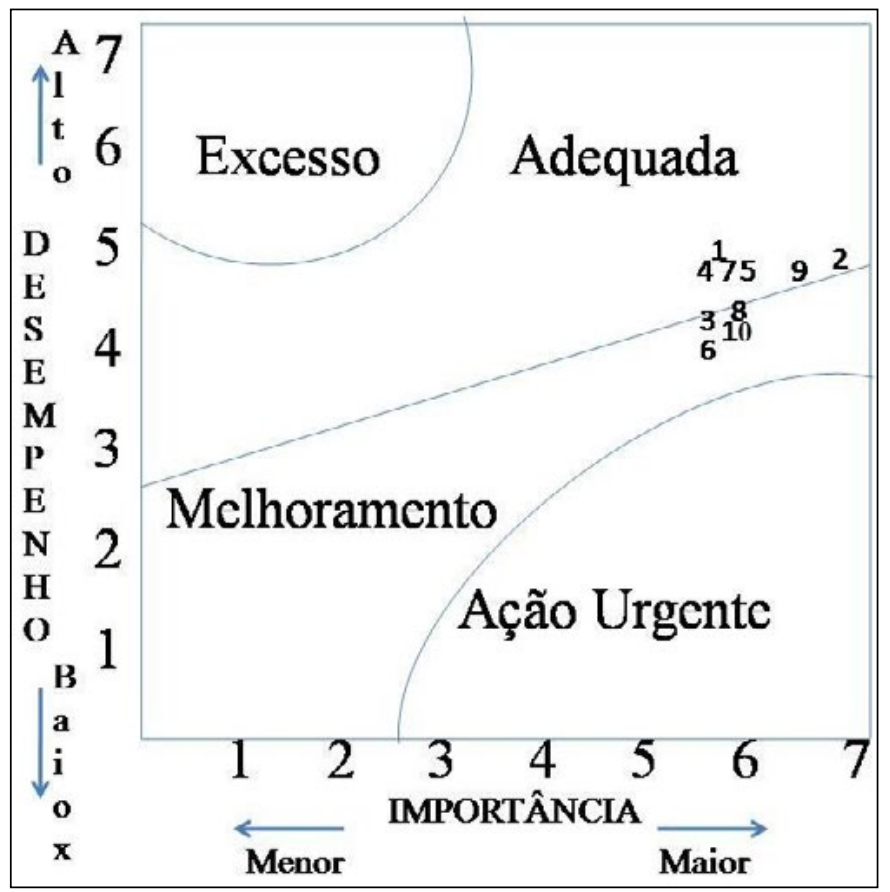

Fonte: Elaborado pelos autores (2017).

Pelas características produtivas do APL ervateiro, há uma alta produção e oferta de erva-mate, o fator disponibilidade de matéria prima (3). Contudo, esse fator estar alocado entre a zona adequada e de melhoramento na matriz importância-desempenho, pode estar associado a variação dessa disponibilidade. Em períodos de preços elevados da matéria prima, os produtores incrementam a produção, há um aumento da disponibilidade, o que resulta na redução do preço. Com preços baixos, alguns produtores acabam adotando a substituição dos ervais por culturas anuais. Essa instabilidade também faz com que algumas ervateiras, principalmente as mais antigas, estabeleçam relaçóes de confiança com produtores, mantendo um preço "padrão", para garantir a matéria-prima para produção.

Os itens que estão alocados na zona de melhoramento, como é o caso dos fatores (6) e (10), disponibilidade de mão de obra e porte e capacidade de maquinários, possuem o valor da importância da média igual a 5,48 e 5,85, respectivamente. Porém, comparado aos fatores anteriores, estes possuem um desempenho mais baixo, 3,74 e 3,96, sendo assim, estas atividades apresentam algum problema para o desempenho do setor e necessitam de ações de melhoramento.

A variância apresentou-se menor em relação ao grau de importância atribuído pelos respondentes do que em relação ao grau de desempenho. $\mathrm{O}$ valor máximo para ambos os fatores em relação à importância foi de 7 pontos e o valor mínimo foi de 4 pontos, sendo assim, observa-se uma menor diferença na opinião dos respondentes em relação a estes fatores. Referente ao grau de desempenho, o valor máximo foi de 6 e 7 pontos e o 
valor mínimo foi de 1 ponto para ambos os fatores, o que revela que, em alguns casos, as atividades de disponibilidade de mão de obra (6) e porte e capacidade de maquinários (10), constitui-se como um problema, com baixo desempenho.

$\mathrm{O}$ valor que ocorre com maior frequência na amostra, em relação ao grau de importância foi de 5 e 6 pontos, e em relação ao grau de desempenho foi de 5 e 4 pontos, respectivamente, configurando estas atividades pela maioria dos respondentes, com maior importância para o desempenho do setor.

A disponibilidade de mão de obra (6), em relação ao resultado da matriz importânciadesempenho, se apresentada como um fator que necessita de açóes de melhoramento no setor. Talvez nesse quesito se deve separar a mão de obra voltada para as atividades de produção a campo, e as atividades produtivas na indústria. $\mathrm{O}$ setor enfrenta uma problemática em relação às atividades à campo, devido ao aumento das exigências e fiscalização dos direitos trabalhistas. Os tarifeiros, como eram chamados os trabalhadores da erva-mate, na maioria, temporários, costumavam se alimentar e, em alguns casos, pernoitar no local da colheita da erva-mate. Essas condições de trabalho são consideradas degradantes, e muitos ervateiros foram notificados.

Os produtores procuram envolver a família na atividade de colheita, no entanto, por se tratar de uma produção característica da agricultura familiar, algumas vezes os filhos dos produtores rurais optam por não seguir na mesma atividade, o que necessita da disposição da mão de obra de fora da região para substituir.

O porte e capacidade dos maquinários (10) e fatores custo da aquisição (8), necessitam de ações de melhoramento, mesmo este último estando em uma zona de transição. Esse fato pode estar associado ao alto custo dos maquinários e equipamentos novos e mais avançados para modernizar a produção. Isto exige espaço físico e grandes esforços dos ervateiros, como a aquisição de crédito para adquiri-los. Também constatou-se que as principais empresas dedicadas na fabricação dos maquinários e equipamentos, não fabricam somente equipamentos específicos para o setor da erva-mate, e sim procuram visualizar em outros setores o que pode ser aplicado e busca realizar testes para aprimorar os equipamentos.

Em relação aos itens que estão alocados na zona adequada, como é o caso dos fatores (4), (1), (7) e (5) (custo de mão de obra; custo de matéria prima, disponibilidade de assistência técnica e capacitação da mão de obra, respectivamente), apresentam os valores da média em relação ao grau de importância igual e acima de 5,37, porém os valores em relação ao grau de desempenho são iguais ou maiores que 4,48 pontos, podendo-se concluir que por possuírem valores altos de desempenho, estes fatores estão sendo trabalhos de forma adequada no setor ervateiro.

Em relação à variância, os valores encontrados para estes fatores foram bastante altos, principalmente considerando o desempenho destas atividades, aliado a isto, nos quatro fatores apresentados o valor máximo foi de 7 pontos para importância e o valor mínimo foi de 1 ponto para o desempenho, o que mostra a falta de homogeneidade entre as respostas obtidas pelos agentes das industrias.

Considerando o valor mais frequente, para o grau de importância, foi de 7 pontos nos fatores (1), (4) e (5) e no fator (7) foi de 6 pontos. Para o grau de desempenho, o 
valor mais frequente foi de 5 pontos para o fator (1), 4 pontos para o fator (4) e 7 pontos para os fatores (5) e (7). Sendo assim, nenhuma das atividades como o custo da matériaprima (1), custo da mão de obra (4), capacidade da mão de obra (5) e disponibilidade de assistência técnica (7), apresentaram-se como um problema, para que sejam necessárias açóes de melhoramento.

Em relação ao custo da matéria prima (1) pode-se dizer que este fator não se apresenta como um problema para os respondentes. Uma das razóes para isso, pode ser as relaçóes de confiança estabelecidas entre os produtores e as indústrias ervateiras e o histórico da atividade no local. Há uma boa oferta de matéria-prima no APL, com vantagens que já foram apontadas anteriormente, mas além disso, essa relação comercial é de longo prazo, o que traz vantagens para o produtor e para o gestor da ervateira. O produtor tem maior garantia de venda da sua erva-mate, por um preço adequado, mesmo que esteja variando. $\mathrm{O}$ gestor da ervateira tem garantia de matéria-prima para sua produção, por um preço justo, que permite a competitividade no mercado. Dessa forma, a relação de confiança estabelecida facilita a negociação de um custo adequado para ambas às partes.

O custo da mão de obra (4) como mencionado por alguns entrevistados, não se constitui como um problema para o setor devido à média salarial da região ser adequada à realidade. A capacitação da mão de obra (5) está na zona adequada da matriz importânciadesempenho, o que pode ser justificado pela presença do conhecimento tácito e cultural local referente à atividade, pois o cultivo da erva-mate predomina como principal atividade econômica da região e trabalhada por várias geraçóes em agricultores familiares. Sendo assim, a maioria da mão de obra da região vem se especializando a aprendendo devido a característica cultura de exploração dessa atividade na região.

$\mathrm{Na}$ disponibilidade de assistência técnica (7) verifica-se a relação com a característica local de produção, o que mobiliza esforços de entidades como a Empresa Brasileira de Pesquisa Agropecuária (Embrapa) e Universidades na construção de pesquisas para subsidiar e especializar a produção de erva-mate, a Empresa de Assistência Técnica e Extensão Rural RS (Emater-RS) como principal entidade de assistência técnica e extensão rural responsável pela transmissão do conhecimento aos agentes do setor e o próprio Instituto Brasileiro da Erva-Mate (Ibramate), que está sediado na região do estudo e desenvolvendo diversas atividades visando promover a expansão e qualificação do setor ervateiro.

A qualidade dos maquinários (7), apesar das poucas empresas fabricantes, tem estabelecido boa relação com os ervateiros e a garantia de assistência técnica principalmente pela proximidade destas empresas com a região das indústrias ervateiras do presente estudo. Foram catalogadas três empresas responsáveis pela fabricação dos equipamentos utilizados para o beneficiamento de erva-mate: uma localizada em Erechim - RS, uma segunda localizada na região do Alto Taquari, no município de Arvorezinha e a terceira localizada no município de Ijuí - RS.

Os itens também alocados na zona adequada, como os fatores (9) e (2), mas que estão próximos da zona de melhoramento, possuem as médias em relação ao grau de importância nos valores de 6,44 e 6,81 e em relação ao grau de desempenho, os valores são 4,41 e 4,78 , respectivamente. Apesar dos valores em relação à média da importância serem os mais altos entre todos os outros fatores alocados nesta matriz, o valor atribuído ao grau de 
desempenho acompanha em uma mesma proporção crescente, fazendo com que estes dois fatores não necessitem de ações de melhoramento.

A variância, em relação ao grau de desempenho, em ambos os fatores foi elevada, de 4,33 e 3,49, respectivamente. Assim como o valor máximo de 7 pontos e o valor mínimo de 1 ponto para os dois fatores, observa-se um alto intervalo entre as respostas. Em relação ao grau de importância, a variância possuiu valores mais baixos e o valor máximo atribuído foi de 7 pontos nos dois fatores, porém o valor mínimo atribuído foi de 4 pontos em relação à qualidade dos maquinários (9) e 5 em relaçáo a qualidade da matéria-prima (2), o que mostra uma maior confiabilidade da importância destas atividades.

O valor mais frequente no fator (9) foi de 7 pontos, tanto para o grau de importância, como para o grau de desempenho. Em relação ao fator (2), o valor mais frequente foi de 7 pontos em relaçáo ao grau de importância e para o grau de desempenho foi de 6 pontos, configurando estas atividades como adequadas, considerando que por mais alta que seja a importância, estes fatores não constituem-se como um problema para o setor, pois o desempenho das atividades também é alto.

Como observado anteriormente, muitas vezes a qualidade da matéria-prima vem sendo avaliada pela proximidade dos agentes, que trabalham a muitos anos no setor, estabelecem relaçóes de confiança, não somente em relação ao preço, mas também no quesito da qualidade. Em certos casos, os gestores de indústrias ervateiras não precisam visitar os ervais e as formas que estes estão sendo manejados para ter certeza da qualidade da erva-mate posta na indústria, devido à garantia da seriedade dos produtores que há muitos anos garantem a matéria-prima para uma mesma indústria.

\subsection{Características produtivas do APL ervateiro Alto Taquari}

A região do Alto Taquari é composta por pequenos municípios de imigração italiana, com uma importante parcela da populaçáo residindo no meio rural e a presença marcante da agricultura familiar. A produção de erva-mate é uma das principais atividades desenvolvidas, em propriedades com áreas médias de 5 a 10 hectares, sendo essa uma atividade registrada historicamente no local.

De acordo com os agentes locais entrevistados, os imigrantes quando chegaram à regiâo já encontraram erva-mate na mata, e as exploravam de modo primitivo, desgalhada a facão, amontoada e sapecada nos carijos, como declaram os agentes locais entrevistados.

\footnotetext{
A erva-mate é tradicional daqui, sempre existiram carijos [...] isso vem de muito tempo, meu pai tinha um carijo (Agente Local 1).

A erva-mate era e continua sendo uma das atividades aonde economicamente ela é importante, socialmente ela é fundamental, ambientalmente nós acreditamos que ela tem um papel extraordinário, e também percebemos que culturalmente também estava incutido dentro das pessoas o cultivo, o manejo da erva-mate (Agente Local 5).
}

Outras atividades agrícolas são desenvolvidas nestes municípios, como a bovinocultura leiteira, integração de suínos, integração de frango e fruticultura. Entretanto, de acordo com os agentes locais entrevistados, a representatividade da erva-mate em relaçáo às outras 
atividades é maior, em torno de 80\%, como citado por alguns entrevistados (Agente Local 3 e Agente Local 6). Nesse sentido, é possível observar o histórico produtivo em relação à erva-mate, sendo esse um ambiente favorável e que confere vantagens competitivas às organizaçóes, que dependem também do seu tamanho, idade, habilidade na gestão e inovação, como mencionado por Porter (1999).

Essa importância se dá também devido ao significativo número de ervateiras existentes no arranjo, sendo contabilizadas na pesquisa de campo, 62 no ano de 2016. No geral, caracterizam-se como organizaçóes de pequeno porte, beneficiando em torno de 100.000 Kg de erva-mate mensalmente, o que corresponde a pouco mais de 6.500 arrobas, tendo de 10 a 20 funcionários. Tratam-se, na sua maioria, de organizaçóes familiares, que geram empregos e agregam valor ao produto localmente. De acordo com Santos e Guarneri (2000), a concentração geográfica de organizaçóes permite ganhos mútuos e operaçôes mais produtivas.

O principal produto é a erva-mate nativa para chimarrão destinada ao mercado interno, sendo essa moída fina e verde, com ou sem açúcar. Contudo, quase a totalidade das ervateiras produz outros tipos de erva-mate para a comercialização, como a erva-mate moída grossa, composto de chás, erva de tereré, natural e com sabores, erva-mate envelhecida, erva-mate orgânica. Além dos tipos mencionados, são ofertados ao consumidor opçóes de tamanho, embalagens e modo de empacotamento. As inovaçóes em produto são estimuladas pelo tecido espacial de conhecimentos construídos em APLs, bem como pela mistura de competição e cooperação em suas relaçóes (COURLET, 2001; BRUSCO, 1992).

A matéria prima beneficiada nas ervateiras é proveniente, salvo casos pontuais, de produtores do próprio APL ervateiro do Alto Taquari. As vantagens da origem local da matéria-prima são destacadas pelos entrevistados. As condiçóes de pagamento diferenciadas foram citadas pelos entrevistados como uma vantagem muito importante, caracterizadas pelo estabelecimento de relaçôes de confiança entre produtor e ervateira. Essa característica possibilita que as transaçóes de compra e venda sejam realizadas sem nenhum tipo de contrato, com condiçóes diferenciadas no que se refere à parcelamento e prazo de pagamento. Sáo registrados casos onde os produtores precisam de dinheiro e pedem adiantamento para a ervateira, para pagar com a colheita da erva-mate, como menciona o agente local 2 , representante do sindicato dos trabalhadores rurais.

Acontece do produtor precisar de dinheiro para pagar alguma conta no comércio, aí ele vai lá na ervateira e pede um adiantamento [...] e as vezes o dono da ervateira também precisa de uns dias pra pagar, e o produtor espera (Agente Local 2).

A maior parte das transações é realizada mediante contratos informais, sem nenhum tipo de registro. Pode-se observar que existe uma relação de confiança criada entre produtor e ervateira, e casos onde o produtor ou a família fornece erva-mate para a mesma ervateira durante muitos anos. Entretanto, como existe um melhor período para a colheita da ervamate, muitas vezes as ervateiras não têm capacidade para receber todo o volume que o produtor tem para fornecer, e acaba pedindo que ele forneça a outra ervateira. Essa relação de confiança é reforçada com disponibilidade de assistência técnica e valorização do produtor, e abalada com o aumento ou queda brusca do preço. 
As relações de confiança estabelecidas entre produtor e ervateira são mencionadas pelos entrevistados como uma vantagem muito importante. Essa relação que é gerada com o tempo, além de facilitar a relaçáo comercial de compra e venda, como já mencionado, possibilita ao gestor da ervateira ter certeza sobre a qualidade da matéria prima que está recebendo do produtor, geralmente não necessitando visitar o erval para comprovar os quesitos de qualidade. A oferta local de matéria-prima e outros insumos, relaçóes de confiança, reduçáo dos custos de transaçáo, são mencionadas como características de um APL, que configuram vantagens às organizaçóes, de acordo com Cassiolato e Szapiro (2003). As relaçôes de confiança ressaltadas pelo produtor, Agente Local 1.

Eu vendo pra mesma ervateira há 20 anos, vem do meu pai [...] eles sabem da qualidade da erva que vendo, por isso, mesmo que o preço baixe muito, eles me pagam um valor justo [...] eles fazem até dia de campo aqui na propriedade (Agente Local 1).

Os atributos de qualidade, fortemente relacionados às relações de confiança estabelecidas com o produtor, é uma das vantagens mencionadas pelos entrevistados como importante e muito importante em relaçáo à origem local da matéria prima. Localmente é possível ter maior controle sobre a qualidade da erva-mate que está sendo adquirida para o beneficiamento. Além da compra de agricultores ao qual já se estabeleceu uma realização de confiança, a proximidade permite a realização de visitas a outros, verificando os quesitos de qualidade, devido às exigências do mercado que atendem, e ainda devido às iniciativas de indicação geográfica da erva-mate no arranjo.

A rapidez na entrega é uma das vantagens destacadas como importante e muito importante em relação à origem local da erva-mate. De acordo com os entrevistados a folha da erva-mate perde qualidade quando fica muito tempo no campo após sua colheita, sofrendo inclusive, um processo de oxidação e escurecimento das folhas. Desta maneira, a redução do tempo entre colheita e beneficiamento preserva características de sabor e qualidade da erva-mate.

Os custos do transporte e assistência técnica dividiram a opiniāo dos entrevistados. Em relação aos custos, pois a reduçáo deste custo possibilita a atribuiçấo de um preço de melhor competitividade no mercado no produto final. Alguns entrevistados declaram que o custo de transporte não tem importância ou é pouco importante, quando da erva-mate tem origem no próprio aglomerado produtivo, justificando que atualmente a maioria dos produtores transportam a erva-mate até a ervateira, não sendo responsabilidade da mesma este custo, como declara o Agente Local 3, intermediário.

O custo de transporte hoje é do produtor, na maioria dos casos, o produtor me liga e pede pra levar a erva em tal ervateira [...] algumas vezes os ervateiros me ligam também, mas aí geralmente é erval próprio dos donos da ervateira (Agente Local 3).

Em relação à assistência técnica prestada localmente, alguns entrevistados a declaram como pouco importante pelo fato de não ser comum as ervateiras prestarem esse serviço aos seus produtores. Entretanto, consideram que, mesmo as ervateiras não fornecendo assistência técnica própria aos produtores, muitas vezes por não ter condiçôes financeiras para isso, 
o município e a região, por ter como uma das principais atividades que movimentam a economia, a ervateira, mobilizam-se esforços de assistência técnica das prefeituras e também de entidades como a Emater - RS e Embrapa.

Em relação à fabricação dos equipamentos utilizados para o beneficiamento de ervamate, se destacaram três empresas: uma localizada em Erechim - RS, como a principal referência; uma segunda localizada no arranjo produtivo do Alto Taquari, no município de Arvorezinha; e a outra citada localiza-se no município de Ijuí - RS. Durante a realização da pesquisa estavam em fase de testes dois equipamentos desta empresa, um da secagem da erva-mate com aproveitamento de calor e utilização de cavacos, e outro do processo de empacotamento, com a introdução de nitrogênio, para ampliação da qualidade e prazo de validade da erva-mate na prateleira.

Quando questionadas sobre vantagens dos equipamentos cuja origem é local, a maioria dos entrevistados declararam a rapidez na entrega como uma vantagem importante, da mesma forma que as informaçóes sobre os equipamentos. Referente a equipamentos, a assistência técnica oferecida foi uma das vantagens também destacadas pelos entrevistados. De acordo com os entrevistados a proximidade com o fornecedor do equipamento, neste caso o próprio arranjo produtivo, favorece a ervateira no caso de qualquer eventual problema que venha a ocorrer, pois a assistência técnica será rápida, não prejudicando o beneficiamento, como tendo que parar a produção, como declara o Agente Local 6.

É muito importante que a gente tenha uma assistência técnica rápida para os equipamentos, porque hoje temos tudo automatizado, a produçáo não pode parar, é um prejuízo grande, a folha pode escurecer e aí não podemos mais utilizar (Agente Local 6).

No que se refere às condiçóes de financiamento e vantagens de preço, houve opinióes diversas, pois para alguns, independentemente da localização da empresa fornecedora do equipamento, este possui um valor e todas as empresas possuem seus limites quanto a prazos e condições especiais de financiamento. Por outro lado, alguns entrevistados acreditam que a empresa fornecedora dos equipamentos estar localizada no arranjo facilita a relaçáo de compra, por um conhecer com quem se está negociando e por isso facilitar as condiçóes de financiamento, bem como negociar melhor preço. A proximidade local entre ervateiros e os fornecedores de equipamentos gera uma sinergia, uma relação de confiança enraizada na história do local e destas organizaçóes, como relatam Cassiolato e Lastres (2003) em seu trabalho.

Das principais vantagens associadas à localização da ervateira no APL ervateiro Alto Taquari, a proximidade com os fornecedores da matéria-prima, os produtores de erva-mate, foi a característica que mais se destacou, sendo considerada muito importante por todos os entrevistados. De acordo com os mesmos, estar próximo aos fornecedores facilita o trabalho para a ervateira, pois a matéria-prima está disponível, próxima, onde consegue-se manter uma relação com os produtores e, muitas vezes, o acompanhamento do erval e da qualidade da erva-mate. Adquirir erva-mate de produtores muito distantes da ervateira, além das questóes logísticas e de transporte, traz consigo uma indefinição da qualidade, risco que as ervateiras não querem enfrentar. 
Vantagens relacionadas a programas governamentais e proximidade com universidades e centros de pesquisa foram consideradas de pouca importância por aproximadamente metade dos entrevistados, em ambos os casos. A justificativa para isso, de acordo com os gestores ervateiros, é que existem poucos programas governamentais voltados ao setor ervateiro, mesmo que o setor movimente a economia de uma regiáo específica. Ainda, que as universidades e centros de pesquisa estáo distantes do setor ervateiro, referindo-se além da distância física, das diferentes realidades do dia a dia do setor com a pesquisa. Essa questão é reforçada pelo Agente Local 5, representante de poder público.

\begin{abstract}
Ainda são poucos os programas e políticas públicas destinadas exclusivamente para o setor ervateiro. Aos poucos estão conquistando seu espaço, mas é um longo caminho, e que depende também do setor, declarando toda sua produção e mostrando sua importância (Agente Local 5).
\end{abstract}

No que concerne à mão de obra nos aglomerados onde estão localizadas as ervateiras, a qualidade desta foi considerada como muito importante pela maioria dos entrevistados. $\mathrm{O}$ custo da mão de obra foi considerado pouco importante por grande parte dos entrevistados, justificado pelo fato de que é baseado na média do salário regional, que não é elevado.

Como a qualidade da mão de obra foi considerada importante, se buscou um maior detalhamento para compreender quais características desse perfil da mão de obra são mais importantes para as ervateiras. Foi possível verificar que a escolaridade formal foi vista como importante pelos entrevistados, contudo, outras características como conhecimento prático ou técnico da produção, iniciativa para resolução de problemas, capacidade para atender novas qualificaçóes e a cultura e o conhecimento local apresentaram maior destaque.

A iniciativa na resolução de problemas foi considerada muito importante pela totalidade dos entrevistados, da mesma forma que o conhecimento prático e/ou técnico da produçáo. Essa característica está relacionada à cultura local, ao conhecimento que é repassado de geração para geração. A capacidade para aprender novas qualificações foi citada como uma característica importante para os ervateiros. A mão de obra qualificada é uma das características mencionadas por Lemos (1997) e Suzigan, Garcia e Furtado (2002) para definição de um arranjo produtivo local, visto que ali há um conhecimento enraizado e um intenso fluxo de informaçóes.

A escolaridade formal teve um grau de importância a ser considerado, contudo, de acordo com os gestores, na atividade ervateira essa escolaridade faz diferença na produçáo quando se adquire um equipamento novo e mais complexo, que exige habilidades diferenciadas dos funcionários. No geral, o conhecimento é repassado de funcionários mais experientes ou até dos proprietários das ervateiras, aos novos funcionários. Lembrando que muitas vezes o funcionário já pode ter trabalhado em outras ervateiras, trazendo conhecimento acumulado daquela experiência.

\title{
5. Consideraçóes finais
}

Este trabalho teve por objetivo discutir a dinâmica de produção da erva-mate no APL ervateiro do Alto Taquari, através de características produtivas locais, e a relação 
destas com os resultados apresentados pela matriz importância-desempenho. Em relação aos principais resultados apresentados, é possível constatar que fatores de produção como custo e qualidade da matéria prima, custo e capacitaçáo da mão de obra, disponibilidade de assistência técnica, por exemplo, alocados na zona adequada da matriz importânciadesempenho, são fatores que tem influência direta das características do arranjo produtivo. Nesse contexto, pode-se aferir que as ervateiras possuem vantagens por estarem em um APL ervateiro, no que concerne aos fatores de produção acima citados.

Em relação ao custo e qualidade da matéria-prima, as relações estabelecidas em um arranjo produtivo, favorecem a negociação, através de acordos informais, que permite um preço justo para o produtor, cobrindo seus custos produtivos, mão de obra, e fortalecendo a atividade; e garantindo ao gestor da ervateira, além do fornecimento da matéria-prima, o preço adequado para se manter competitivo no mercado. Essa confiança se estende em relação à qualidade da matéria-prima que está sendo ofertada pelo produtor.

Da mesma forma, em relação à mão de obra, os conhecimentos tácitos e a transmissão de informações entre os agentes em um APL são características que beneficiam as organizaçóes, no que concerne a sua atividade produtiva. Isso foi constatado no APL ervateiro do Alto Taquari, sendo a capacitação da mão de obra, através da realização de cursos ou pela experiência do próprio processo produtivo, é valorizada pelos entrevistados, e o custo considerado adequado à realidade, fazendo com que esses fatores se encontrem na zona adequada em relação a sua importância e desempenho.

É preciso destacar também os fatores que precisam ser melhorados, como a disponibilidade de matéria-prima, custo de aquisição, porte e capacidade de maquinários. O fator da disponibilidade da matéria-prima, como apresentado nos resultados, pode ser justificado pela instabilidade da sua disponibilidade, o que está associado ao preço e a uma característica que também é inerente aos APLs, relações específicas em uma mistura de competição e cooperação. Os custos, porte e capacidade de maquinários talvez seja um "ponto fraco" do APL, visto que há apenas uma empresa que fabrica esses equipamentos no local, náo sendo essa especializada no setor ervateiro, e ainda, tendo os equipamentos mais novos, um valor elevado para o porte das organizaçóes.

Mesmo tendo importância econômica, social e ambiental, o Arranjo Produtivo Local ervateiro do Alto Taquari carece de incentivo através de políticas públicas. Atualmente não existem linhas de financiamento específicas para produtores e beneficiadores de erva-mate, os obrigando a realizar investimentos com recurso próprio ou empréstimos com taxas de juros pouco atrativas. Algumas iniciativas do governo do Estado do Rio Grande do Sul podem ser mencionadas, como o Fundo de Desenvolvimento e Inovação da Cadeia Produtiva da Erva-Mate (FUNDOMATE) e a Câmara Setorial da Erva-mate, mas são incipientes frente a necessidade de investimentos que o arranjo careceria.

$\mathrm{O}$ estudo não apresentou nenhum fator de produção na zona de excesso e na zona urgente, o que é questionável quando se analisa somente as falas dos entrevistados. Nesse sentido, a utilização de uma escala pode ser uma limitação na identificação de problemas em um setor, pela tendência dos entrevistados em atribuição de valores médios. Em estudos futuros, a confirmação dos fatores e suas respectivas localizaçôes na matriz de importânciadesempenho, pelo retorno a campo é um passo metodológico interessante. Além disso, 
são sugeridos estudos que relacionam às características dos APLs a outros fatores, como de mercado e logística.

\section{Referências}

BETTO, L., FERREIRA, G. M. V., TALAMINI, E. Aplicação da Matriz Importância Desempenho no Varejo de Alimentos: Um Caso no Rio Grande do Sul. Revista da Micro e Pequena Empresa, v.4, n.2, p. 64-79. Campo Limpo Paulista, 2010.

BRUSCO, S. Small firms and the provision of real services. In: PYKE, F; SENGENBERGER, W. (Ed.) Industrial districts and local economic regeneration. Geneva: International Institute for Labour Studies, 1992. p. 177-196.

CASSIOLATO, J. E.; LASTRES, H. M. M. O foco em arranjos produtivos e inovativos locais de micro e pequenas empresas. In: LASTRES, H. M. M.; CASSIOLATO, J. E.; MACIEL, M. L. (Org.). Pequena empresa: cooperaçáo e desenvolvimento local. Rio de Janeiro: Relume Dumará; UFRJ/Instituto de Economia, 2003. Cap. 1, p. 21-34.

CASSIOLATO, J. E.; SZAPIRO, M. Arranjos e sistemas produtivos e inovativos locais no Brasil. Rio de Janeiro: Instituto de Economia da UFRJ, set. 2003.

COURLET, C. Novas dinâmicas de desenvolvimento e Sistemas Industriais Localizados (SIL). Ensaios FEE, Porto Alegre, v. 14, n. 1, p. 9-25, 1993.

COURLET, C. Les systèmes productifs locaux: de la definition au modèle. In: DÉLÉGATION À L'AMÉNAGEMENT DU TERRITOIRE ET À L'ACTION RÉGIONALE - DATAR. Réseaux d'entrepriseset territories: regards sur lêssy stèmes productifs locaux. Paris: La Documentation Française, 2001. p. 17-61.

EDQUIST, C. (Ed.). Systems of innovation: technologies, institutions, and organizations. London: Pinter, 1997.

GIL, A. C. Como elaborar projetos de pesquisa. 4. ed. São Paulo: Atlas, 2007. INSTITUTO BRASILEIRO DE GEOGRAFIA E ESTATÍSTICA- IBGE. Produção agrícola municipal, 2015. Rio de Janeiro, 2015. Disponível em: <http://www2.sidra. ibge.gov.br/bda/tabela/protabl.asp? $\mathrm{c}=1613 \& \mathrm{z}=\mathrm{t} \& \mathrm{o}=11 \& \mathrm{i}=\mathrm{P}>$. Acesso em: 14 ago. 2017.

KOWALSKI, F. D., FERNANDES, F. C. Análise dos Controles Internos Relacionados às Atividades Ambientais das Cooperativas de Energia Elétrica por meio da Matriz Importância-Desempenho de Slack: Um Estudo do Estado de Santa Catarina. XXXII Encontro da ANPAD. Rio de Janeiro, RJ. Anais... 2008.

LASTRES, H. M. M.; LEMOS, C.; VARGAS, M. Novas políticas na economia do conhecimento e do aprendizado. Nota Técnica 25, Bloco 3. In: CASSIOLATO, J.; 
LASTRES, H. (Org.). Arranjos e sistemas produtivos locais e as novas políticas de desenvolvimento industrial e tecnológico. Rio de Janeiro: IE/UFRJ, 2000.

LEMOS, C. Notas preliminares do projeto arranjos locais e capacidade inovativa em contexto crescentemente globalizado. Rio de Janeiro: IE/UFRJ, 1997.

MARKUSEN, A. R. et al. (Ed.). Second tier cities: rapid growth beyond the metropolis. London: University of Minnesota Press, 1999.

MARSHALL, A. Princípios da economia: tratado introdutório. São Paulo: Abril Cultural, 1982.

MORAIS, C. Descriçáo, Análise e Interpretação de Informação Quantitativa. Escola Superior de Educação, Instituto Politécnico de Bragança. Portugal, 2010.

PORTER, M. E. Clusters and the New Economics of Competition. Harvard Business Review. 1998. p. 77-90.

PORTER, M. E. Competiçáo - on competition: estratégias competitivas essenciais. Rio de Janeiro: Campus, 1999.

PUGA, F. P. Alternativas de apoio a MPMES localizadas em arranjos produtivos locais. [S.L.]: BNDES, 2003. (Texto para discussão, n. 99). Disponível em: < http://www. bndes.gov.br/SiteBNDES/export/sites/default/bndes_pt/Galerias/Arquivos/conhecimento/ td/td-99.pdf>. Acesso em: 07 mar. 2017.

RABELLOTTI, R. Is there an "Industrial District Model”? Footwear districts in Italy and Mexico compared. World Development, [S.1.], v. 23, n. 1, p. 29-41, 1995. Disponível em: <http://www.sciencedirect.com/science/article/pii/0305750X94001036>. Acesso em: 08 mar. 2017.

RICHARDSON, R. J. Pesquisa social: métodos e técnicas. 3. ed. São Paulo: Atlas, 2009.

SANTOS, A. M. M. M.; GUARNERI, L. S. Características gerais do apoio e arranjos produtivos locais. Revista do BNDES, n. 12, p. 195-204, Set. 2000.

SCHMITZ, H. Collective efficiency: growth path for small-scalle industry. The Journal of Development Studies, London, v. 31, n. 4, p. 529-566, 1995.

SCHMITZ, H. Pequenas empresas e especialização flexível em países menos desenvolvidos. São Paulo: FEA/USP, 1989.

SCOTT, A. J. The geographic foundations of industrial performance. In: CHANDLER JUNIOR, A. D.; HAGSTROM, P.; SOLVELL, O. (Ed.). The dynamic firm: the role of 
technology, strategy, organization and regions. Oxford: Oxford University Press, 1998. Cap. 16, p. 384-401.

SLACK, Nigel; CHAMBERS, Stuart; JOHNSTON, Robert. Administração da Produção. 2 ed. São Paulo: Atlas, 2002.

SPSS ${ }^{\circledast}$. Statistical Package for Social Sciences, 2003.

STORPER, M. The resurgence of regional economies, 10 years later. In: STORPER, M. The regional world: territorial development in a global economy. New York; London: The Guil ford Press, 1997. p. 3-25.

SUZIGAN, W. Aglomerações industriais, como focos de políticas. Revista de Economia Política, v. 21, n. 3, p. 28-39, Jul./Set. 2001.

SUZIGAN, W.; GARCIA, R.; FURTADO, J. Governança de sistemas de MPMEs em clusters industriais. Trabalho apresentado no Seminário Internacional Políticas para sistemas produtivos locais de MPMEs, Rio de Janeiro, 2002.

TRIVIÑOS, A. N. S. Introduçáo à pesquisa em ciências sociais: a pesquisa qualitativa em educação. São Paulo: Atlas, 1987.

VALERIANO, M. F., TALAMINI, E., OLIVEIRA, L. Diagnóstico do Clima Organizacional Utilizando a Matriz de Importância-Desempenho: Aplicação em uma Pequena Empresa do Agronegócio. Revista da Micro e Pequena Empresa, v.5, n.1, p.2035, Campo Limpo - SP, 2011.

VARGAS, M. A. Proximidade territorial, aprendizado e inovaçáo: um estudo sobre a dimensão local dos processos de capacitação em arranjos e sistemas produtivos locais. 2002. 256 f. Tese (Doutorado em Economia) - Programa de Pós-Graduação em Economia, Universidade Federal do Rio de Janeiro, Rio de Janeiro, 2002. 